\title{
Insulin Resistance and Lipid Profile in Morbidly Obese Patients After Laparoscopic Total Gastric Vertical Plication
}

\author{
Thiow Kong $\operatorname{Ti}^{1^{*}}$ \\ ${ }^{1}$ National University Hospital, Singapore
}

\section{A R T I C L E I N F O}

Article type:

Letter to Editor

Article history:

Received: 01 Mar 2012

Revised: 05 May 2012

Accepted: 15 May 2012

Keywords:

Gastrectomy

Obesity

Hormones

\section{Dear Editor,}

In recent years sleeve (vertical) gastrectomy has been increasingly used as a stand-alone procedure, effecting significant weight reduction, resolution of obesity comorbidities and minor nutritional deficits at 5 years of follow-up $(1,2)$. Sleeve gastrectomy has also been shown to have comparable early changes in gastro-intestinal hormones as the more complicated Roux-en-Y gastric bypass surgery for morbidly obese type II diabetic subjects (3). The new procedure of laparoscopic total gastric vertical plication (LTGP), used by Golpaie et al. has similarities with sleeve gastrectomy in deriving its bariatric effect through reduction of stomach capacity (4).

It is thus timely that LTGP is being investigated as an alternative to sleeve gastrectomy. Unsurprisingly, Golpaie et al. have found that significant weight loss and improvement in lipid profile and insulin resistance occurred within six weeks of LTPG in 15 patients (4). As pointed out by Talepour et al. technical details of LTGP i.e. anterior versus greater curvature plication and remnant stomach

\footnotetext{
${ }^{*}$ Corresponding author: Thiow Kong Ti, National University Hospital, Lower Kent Road, Singapore. Tel: +65-97336652, Fax: +65-67348469, E-mail: thiow_ kong_ti@nuhs.edu.sg

DOI:10.5812/jmiss.4688

Copyright (C) 2012, Minimally Invasive Surgery Research Center and Mediterranean \& Middle Eastern Endoscopic Surgery Association. This is an open-access article distributed under the terms of the Creative Commons Attribution License, which permits unrestricted use, distribution, and reproduction in any medium, provided the original work is properly cited.
}

Please cite this paper as:

Ti Tk. Insulin Resistance and Lipid Profile in Morbidly Obese Patients After Laparoscopic Total Gastric Vertical Plication. J Minim Invasive Surg Sci.2012;1(2): 85-6. DOI:10.5812/jmiss.4688

capacity needs clearer definition (5). These authors have also pointed out possible cost advantage, reversibility and lower leakage complications with LTPG. These need to be verified by a larger experience. Nevertheless, there is the potential disadvantage of the sequestrated plicated part of the stomach being out of reach for gastroscopic surveillance and hence delay in diagnosis of subsequent pathology. This would be a consideration, especially in East Asia where there is a high incidence of gastric cancer.

\section{Authors' Contribution}

Thiow Kong Ti contributed 100\% to prepare this article.

\section{Financial disclosure}

The author declares that he has no connecting interest and no relevant financial interest.

\section{References}

1. Deitel M, Gagner M, Erickson AL, Crosby RD. Third International Summit: Current status of sleeve gastrectomy. Surg Obes Relat Dis. 2011;7(6):749-59.

2. Kehagias I, Spyropoulos C, Karamanakos S, Kalfarentzos F. Efficacy of sleeve gastrectomy as sole procedure in patients with clinically severe obesity (BMI $<1=50 \mathrm{~kg} / \mathrm{m}(2))$. Surg Obes Relat Dis. 2012.

3. Romero F, Nicolau J, Flores L, Casamitjana R, Ibarzabal A, Lacy A, et al. Comparable early changes in gastrointestinal hormones af- 
ter sleeve gastrectomy and Roux-En-Y gastric bypass surgery for morbidly obese type 2 diabetic subjects. Surg Endosc. 2012:[Epub ahead of print].

4. Golpaie A, Hosseinzadeh-Attar MJ, Hoseini M, Karbaschian Z. Changes in Lipid Profile and Insulin Resistance in Morbidly Obese Patients Following Laparoscopic Total Gastric Vertical Pli- cation. J Minim Invasive Surg Sci. 2012;1(2): 24-9.

5. Talebpour M, Amoli BS. Laparoscopic total gastric vertical plication in morbid obesity. J Laparoendosc Adv Surg Tech A. 2007;17(6):793-8. 